\title{
EL CENTRO DE INTERESES DE LA PERSONA JURÍDICA: COMENTARIO A LA SENTENCIA DEL TJUE DE 17 DE OCTUBRE DE 2017, BOLAGSUPPLYSNINGEN OÜ, INGRID ILSJAN Y SVENSK HANDEL AB, C-194/16
}

\author{
CENTRE OF INTERESTS OF THAT PERSON: COMMENTS \\ TO THE CJUE JUDGEMENT OF 17 OCTUBER 2017, \\ BOLAGSUPPLYSNINGEN OÜ, INGRID ILSJAN Y SVENSK \\ HANDEL AB, C-194/16
}

\author{
Antonio Merchán Murillo \\ Profesor de Derecho Internacional Privado \\ Universidad Pablo de Olavide
}

Recibido: 10.07.2018 / Aceptado: 20.07.2018

DOI: https://doi.org/10.20318/cdt.2018.4410

\begin{abstract}
Resumen: La Sentencia TJUE de 17 de octubre de 2017, Bolagsupplysningen Oü, Ingrid Ilsjan y Svensk Handel Ab, asunto C-194/16, recoge una nueva interpretación del artículo 7,2 del Reglamento $1215 / 2012$, en relación con las obligaciones extracontractuales, determinando que las personas jurídicas pueden presentar una demanda por vulneración de sus derechos de personalidad ante los tribunales del Estado miembro donde se encuentra su centro de intereses. Este centro de interés vendrá determinado por el lugar en el que ejerce la parte esencial de su actividad económica.

Palabras clave: Reglamento 1215/2012, obligaciones extracontractuales, derechos de la personalidad, centro de interés.

Abstract: The CJUE judgement of 17 Octuber 2017, Bolagsupplysningen OÜ, Ingrid Ilsjan y Svensk Handel Ab, C-194/16, refers to a new interpretation regarding Art. 7,2 of Regulation 1215/2012, in relation to non-contractual obligations, and determines that legal persons can file a claim for violation of their personality rights before the Member State's courts where they locate their center of interests. This center of interest will be determined by the place where the essential part of its economic activity is exercised.
\end{abstract}

Keywords: Regulation 1215/2012, non-contractual obligations, rights relating to personality, center of interest.

Sumario: I. Introducción. II. Supuesto de hecho. III. Contextualización y análisis de la sentencia. 1. Evolución del criterio jurisprudencial. A. El doble foro: el lugar donde se haya materializado el daño o el lugar del hecho causal que originó el daño. B. La tesis mosaico: la totalidad del daño en el lugar de origen o parcialmente en cada país donde se hubiera materializado el daño. C. El centro de interés como criterio adicional de conexión con el foro. D. El centro de interés como criterio de competencia para las personas jurídicas. E. Competencia judicial para la supresión y rectificación de información inexacta. IV. Conclusiones. 


\section{Introducción}

1. La Sentencia del TJUE, de 17 de octubre de 2017, asunto C-194/16, Bolagsupplysningen OÜ, Ingrid Ilsjan y Svensk Handel AB, añade una nueva línea interpretativa al artículo 7,2 del Reglamento 1215/2012, del Parlamento Europeo y del Consejo, de 12 de diciembre de 2012, relativo a la competencia judicial, el reconocimiento y la ejecución de resoluciones judiciales en materia civil y mercantil.

2. En esta Sentencia el TJUE tiene por objeto una petición de decisión prejudicial planteada, con arreglo al artículo 267 TFUE, por el Riigikohus (Tribunal Supremo, Estonia), en relación a: si los órganos jurisdiccionales estonios pueden declararse competentes para conocer de esta acción basándose en el centro de intereses de la recurrente, teniendo en cuenta que el Tribunal de Justicia ha aplicado en otras ocasiones este criterio de competencia respecto a personas físicas, pero nunca hasta ahora a personas jurídicas; en caso afirmativo, desea saber cómo debe determinarse el centro de intereses de una persona jurídica; finalmente, en caso de que la competencia de los órganos jurisdiccionales estonios se limite a las situaciones en las que los daños y perjuicios se hayan ocasionado en Estonia, el órgano jurisdiccional remitente se pregunta si puede ordenar a la federación sueca que rectifique y suprima la información controvertida.

3. Como puede observarse, se presenta una situación novedosa respecto a la jurisprudencia anterior ${ }^{1}$ : que una persona jurídica solicita, con carácter principal, que se rectifique y suprima información disponible en Internet y, así, determinar si la protección de los derechos de la personalidad en tanto que derechos fundamentales puede extenderse asimismo a las personas jurídicas².

4. Estas circunstancias fácticas permiten al Tribunal añadir y/o actualizar el criterio interpretativo en materia delictual o cuasidelictual establecido en la Sentencia, de 7 de marzo de 1995, asunto C-68/93, Fiona Shevill, Ixora Trading Inc., Chequepoint SARL, Chequepoint International Ltd y Presse Alliance SA, en un caso de difamación a través de medios de comunicación impresos, y en la Sentencia, de 25 de octubre de 2011, asunto C-509/09 y C-161/10, eDate Advertising y otros, en relación a los daños causados a la reputación de una persona física, mediante información publicada en Internet.

\section{Supuesto de hecho}

5. Bolagsupplysningen OÜ es una sociedad, con domicilio social establecido en Tallin (Estonia), que realiza la mayor parte de sus negocios en Suecia, la Sra. Ingrid Ilsjan es empleada de la citada sociedad. Svensk Handel AB es una federación profesional sueca. Esta última incluyó a Bolagsupplysningen OÜ en una lista negra publicada en su sitio web, afirmando que ésta comete estafa y fraude. El foro de discusión del sitio web recibió unos 1.000 comentarios en respuesta a la inclusión en la lista negra, entre los que figuraban llamamientos al uso de la violencia contra la recurrente y sus empleados, en la que se incluía la Sra. Ingrid Ilsjan.

6. Ante esto Bolagsupplysningen OÜ y la Sra. Ingrid Ilsjan demandaron ante el Tribunal de Primera Instancia de Harjuu (Estonia) a Svensk Handel AB, solicitando que se rectifique la información publicada y se supriman los comentarios de su sitio web. La recurrente también solicitó una indemnización por los daños y perjuicios ocasionados, en particular, en concepto de lucro cesante, por valor de 56.634,99 euros. La Sra. Ilsjan solicitó una indemnización por los daños morales sufridos. La recurrente y la Sra. Ilsjan alegaron que habían sufrido un perjuicio como consecuencia de la actuación de la recurrida. En su opinión, la publicación de información inexacta afectó negativamente a la actividad económica de la empresa en Suecia.

\footnotetext{
1 A.L. Calvo Caravaca/J. Carrascosa González, Derecho Internacional Privado, vol. II, $18^{\mathrm{a}}$ ed., Comares, Granada, 2018, pp. 1265-1286.

2 Conclusiones del Abogado General, Michal Bobek, presentadas el 13 de julio de 2017, Bolagsupplysningen OÜ, Ingrid Ilsjan contra Svensk Handel AB, asunto C-194/16 (ECLI:EU:C:2017:554), apartado 36.
} 
7. El Tribunal de Primera Instancia denegó la admisión a trámite de la demanda y el Tribunal de Apelación confirmó la falta de competencia internacional de los órganos jurisdiccionales estonios. Cuando el asunto llegó al Tribunal Supremo, éste decidió sustanciar por separado las pretensiones de Bolagsupplysningen y las pretensiones de la Sra. Ilsjan considerando que, en relación con esta última el asunto debía devolverse a este último tribunal para que se pronunciara sobre la admisibilidad de las pretensiones de la Sra. Ilsjan. Con relación a Bolagsupplysningen, el Tribunal Supremo decidió suspender el procedimiento y plantear al TJUE una serie de preguntas sobre su competencia para dirimir con claridad el asunto.

\section{Contextualización y análisis de la sentencia}

8. Las reglas para determinar la competencia figuran en el Capítulo II del Reglamento 1215/2012. La norma general se regula en la Sección 1, concretamente, en el artículo 4,1, que consagra el foro general del domicilio del demandado, en el que se indica que "salvo lo dispuesto en el presente Reglamento, las personas domiciliadas en un Estado miembro estarán sometidas, sea cual sea su nacionalidad, a los órganos jurisdiccionales de dicho Estado", consagrándose que la competencia judicial debe regirse siempre por este principio, excepto en algunos casos muy concretos en los que el objeto del litigio o la autonomía de las partes justifique otro criterio de conexión.

9. Este foro se completa, como indica el Considerando 16, con otros foros alternativos a causa de la estrecha conexión existente entre el órgano jurisdiccional y el litigio o para facilitar una buena administración de justicia. Esto nos sitúa en el artículo 5,1 que dispone que "las personas domiciliadas en un Estado miembro solo podrán ser demandadas ante los órganos jurisdiccionales de otro Estado miembro en virtud de las normas establecidas en las secciones 2 a 7 del presente capítulo". Sobre la base del artículo 7,2 (antiguo artículo 5,3 del Reglamento 44/2000 y artículo 5,3 del Convenio de Bruselas), situado en la sección 2 , se podrán entablar acciones extracontractuales, ante el órgano jurisdiccional del lugar donde se produzca o se vaya a producir el hecho dañoso.

10. El artículo 7,2 se basa en la estrecha conexión, de la disputa y los tribunales donde se produce o pueda producirse el hecho dañoso, con objeto de garantizar la seguridad jurídica y evitar la posibilidad de que una persona sea demandada ante un órgano jurisdiccional de un Estado miembro que no hubiera podido prever razonablemente. Esta cuestión resulta de especial relevancia en relación con los litigios relativos a obligaciones no contractuales derivadas de vulneraciones del derecho a la intimidad y de los derechos de la personalidad, incluida la difamación, como es el caso del que viene a tratarse en esta Sentencia.

\section{Evolución del criterio jurisprudencial}

\section{A. El doble foro: el lugar donde se haya materializado el daño o el lugar del hecho causal que originó el daño.}

11. Este criterio comenzó con la Sentencia del TJCE, de 30 de enero de 1976, asunto 21/76, Handelskwekerij G. J. Bier BV contra Mines de potasse d'Alsace SA. En este asunto la sociedad neerlandesa Bier, que poseía en las cercanías de Rotterdam importantes viveros irrigados con las aguas del Rin, y la fundación Reinwater de Amsterdam, emplazaron ante el Tribunal de Rotterdam, a la sociedad Mines de potasse d'Alsace, con domicilio social en Mulhouse (Francia), solicitando la indemnización de los daños causados por la contaminación de las aguas del Rin a causa del vertido de cerca de 11.000 toneladas de cloruro al día en un canal que desemboca en dicho río.

12. El comportamiento de la demandada, a la que se atribuye la producción del daño, tuvo lugar, en Francia, mientras que el perjuicio se produjo en los Países Bajos. Las partes actoras sometieron su 
demanda al Juez neerlandés, estimando que Rotterdam era, según artículo 5,3 del Convenio de Bruselas (artículo 5,3 del Reglamento 44/2000 y artículo 7,2 del Reglamento 1215/2012), "el lugar donde se había producido el hecho dañoso". Por su parte la demandada planteó la excepción de incompetencia del órgano jurisdiccional neerlandés dado que, en su opinión, el eventual hecho ilícito debía considerarse localizado en Francia, en la circunscripción del Juez de Mulhouse y éste sería por tanto el único órgano jurisdiccional competente, con arreglo al citado artículo, para conocer de la demanda de indemnización.

13. Mediante sentencia de 12 de mayo de 1975, el Tribunal de Rotterdam admitió la excepción de incompetencia por cuanto el hecho dañoso objeto del procedimiento sólo puede ser el vertido de residuos en el Rin, efectuado en Francia. El Tribunal de apelación de La Haya, ante el cual los demandantes recurrieron esta decisión, sometió al Tribunal de Justicia, de acuerdo con el artículo 3 del Protocolo de 3 de junio de 1971 relativo a la interpretación del Convenio de 27 de septiembre de 1968, la siguiente cuestión prejudicial: ¿debe interpretarse en el sentido de "lugar en el que se ha producido el daño" o de "lugar donde se ha cometido el hecho que ha tenido consecuencias dañosas"?

14. El TJCE estableció que el significado de la expresión "el lugar donde se hubiere producido el hecho dañoso", debe determinarse de manera que se reconozca al demandante la opción de ejercitar su acción, bien en el lugar donde se haya materializado el daño, bien en el lugar en el que se haya producido el hecho causante ${ }^{3}$. De ello resulta que la acción judicial frente al demandado puede ser entablada, a elección del demandante, ante el Tribunal o bien del lugar donde ha sobrevenido el daño, o bien del lugar donde se ha producido el hecho causante que ocasiona el daño ${ }^{4}$.

\section{B. La tesis mosaico: la totalidad del daño en el lugar de origen o parcialmente en cada país donde se hubiera materializado el daño}

15. En este supuesto resulta preciso analizar la Sentencia del TJUE, de 7 de marzo de 1995 , asunto C-68/93, Fiona Shevill, Ixora Trading Inc., Chequepoint SARL y Chequepoint International Ltd contra Presse Alliance SA. En este asunto se refería a la publicación de un artículo difamatorio en Francia. Presse Alliance SA, que edita el periódico France-Soir, publicó el 23 de septiembre de 1989 un artículo relativo a una operación efectuada por la brigada de estupefacientes de la policía francesa en una de las oficinas de cambio explotadas en París por Chequepoint SARL. Dicho artículo, basado en informaciones proporcionadas por la agencia France Presse, mencionaba a la sociedad Chequepoint, así como a una joven llamada Fiona Shevill-Avril. La Sra. Shevill, nacional británica con domicilio en North Yorkshire en Inglaterra fue empleada por Chequepoint SARL durante tres meses en París, volviendo posteriormente a Inglaterra. Ixora Trading Inc., que no es una sociedad inglesa, explota oficinas de cambio en Inglaterra desde 1974 bajo el nombre de Chequepoint. Chequepoint International Ltd, sociedad holding belga con domicilio social en Bruselas, controla Chequepoint SARL e Ixora Trading Inc.

16. Los cuatro demandantes instaron ante la High Court of England and Wales, una acción por difamación contra Presse Alliance SA reclamando daños y perjuicios por los ejemplares de FranceSoir distribuidos tanto en Francia como en los demás países europeos, incluidos los vendidos en Inglaterra y en el País de Gales. Ulteriormente, los demandantes modificaron sus pretensiones abandonando toda referencia a los ejemplares vendidos fuera de Inglaterra y del País de Gales. Como en el Derecho inglés existe una presunción de perjuicio en materia de difamación, los demandantes no tuvieron que aportar la prueba del perjuicio derivado de la publicación del artículo controvertido. Presse Alliance SA impugnó

3 STJUE, de 30 de enero de 1976, Handelskwekerij G. J. Bier BV contra Mines de potasse d'Alsace SA, asunto 21/76, apartado 6 .

${ }^{4}$ La tesis de la ubicuidad no persigue favorecer a la víctima. Sin embargo, es inevitable concluir que, en la práctica, potencia no el forum victimae, pero si el forum actoris. Con frecuencia, el país donde se verifica el resultado lesivo es el país donde está el domicilio del demandante, sea éste la presunta víctima o el presunto responsable (A.L. CAlvo CaravaCa/J. Carrascosa González, "Obligaciones extracontractuales" en A.L. Calvo Caravaca/J. Carrascosa González (Dirs.), Derecho Internacional Privado, Ed. Colex, Madrid, 2012, pp. 1300-1413). 
la competencia de la High Court of England and Wales para conocer del litigio, alegando que, con arreglo al 5,3 del Convenio de Bruselas, no se había producido ningún hecho dañoso en Inglaterra.

17. En este caso el TJUE viene a decir que si el hecho se produce en un Estado miembro y los daños se manifiestan en varios, el demandante puede optar entre reclamar la totalidad del daño en el lugar de origen, o parcial en cada país donde se hubiera materializado el daño ${ }^{5}$. De esta forma, determino que el lugar del hecho causal sólo puede ser el del lugar del establecimiento del editor de la publicación controvertida, en la medida en que constituye el lugar de origen del hecho dañoso ${ }^{6}$, a partir del cual la difamación se ha manifestado y difundido. El órgano jurisdiccional del lugar del establecimiento del editor de la publicación difamatoria debe, por tanto, ser competente para conocer de la acción de reparación de la integridad del perjuicio causado por el acto ilícito. Por regla general, dicho foro coincidirá con el del domicilio del demandado, criterio de competencia establecido artículo 2,1 del Convenio (artículo 2 del Reglamento 44/2000, ahora artículo 4 del Reglamento 1215/2012).

18. Por otro lado, el Tribunal dio un paso más respecto al asunto $21 / 76$ elaborando lo que se conoce como la teoría del mosaico, sobre la base de la difusión de copias impresas de una publicación específica en un Estado miembro determinado. En este sentido, estableció que, en el caso de una difamación internacional a través de la prensa, el ataque de una publicación difamatoria al honor, a la reputación y a la consideración de una persona física o jurídica se manifiesta en los lugares en que la publicación ha sido difundida, cuando la víctima es allí conocida ${ }^{7}$. Por lo que los órganos jurisdiccionales de cada Estado, en que se haya difundido la publicación difamatoria y en que la víctima alegue haber sufrido un ataque a su fama, son competentes para conocer de los daños causados en dicho Estado a la reputación de la víctima, ya que se encuentran territorialmente mejor situados para determinar el alcance del daño ${ }^{8}$.

\section{El centro de interés como criterio adicional de conexión con el foro}

19. Con el surgimiento de internet aparece la conveniencia de adaptar los requisitos legales existentes, para evitar que se constituyan obstáculos, al proyectarse sobre las relaciones sociales o comerciales a través de la red. Por ello, analizaremos la Sentencia del TJUE, de 25 de octubre de 2011. Asunto C-509/09 y C-161/10, eDate Advertising GmbH y otros contra X y Société MGN Limited.

20. Si bien, a través del asunto 21/76 (sentencia Minas de Potasa de Alsacia) el Tribunal estableció que el foro especial de responsabilidad delictual o cuasidelictual en dichos casos terminara coincidiendo con el foro general del domicilio del demandado, el Tribunal de Justicia interpretó el referido artículo 5,3 del Reglamento 44/2000 (antiguo artículo 5,3 del Convenio de Bruselas y actual artículo 7,2 Reglamento 1215/2012), en el sentido de que el mismo admite dos foros alternativos, a elección del demandante: uno en el lugar de producción del hecho causal, y otro en el de producción efectiva del daño.

21. Con el asunto C-68/93, el planteamiento de la sentencia, centrado en la producción de daños materiales, se extendió a los supuestos de daños inmateriales. En dicho asunto, el Tribunal de Justicia admitió la aplicabilidad del planteamiento recién expuesto a supuestos de vulneración de derechos de la personalidad. Así, en el caso de difamación internacional ${ }^{9}$, a través de la prensa, el ataque al honor, a la reputación y a la consideración de una persona física o jurídica se manifiesta en los lugares en que la

5 STJUE, de 7 de marzo de 1995, Fiona Shevill, Ixora Trading Inc., Chequepoint SARL, Chequepoint International Ltd y Presse Alliance SA, asunto C-68/93, apartado 14.

${ }^{6}$ N.Goñ UrRiZA, "la concreción del lugar donde se ha producido el hecho dañoso en el art. 5,3 del Reglamento Bruselas I-bis: nota a la STJCE de 16 de julio de 2009”, CDT, 2011, pp. 290-295.

7 STJUE, de 7 de marzo de 1995, Fiona Shevill, Ixora Trading Inc., Chequepoint SARL, Chequepoint International Ltd y Presse Alliance $S A$, asunto C-68/93, apartado 29.

8 M.Eslava Rodríguez, "el locus delicti commissi en los ilícitos contra la vida privada cometidos a través de Internet", Informática y Derecho, 34, 20014, pp. 15-38.

9 Eslava Rodríguez, M.: "el locus delicti commissi en los ilícitos contra la vida privada cometidos a través de Internet", Informática y Derecho, 34, 20014, pp. 15-38. 
publicación ha sido difundida ${ }^{10}$, si la víctima es conocida en ese lugar. En este supuesto, sin embargo, el titular del derecho de la personalidad afectado tan sólo podría reclamar en dicho foro los daños sufridos en ese Estado.

22. Así, a través del artículo 5,3 del Reglamento 44/2001, para los casos de lesiones a los derechos de la personalidad a través de medios de comunicación, se presentan dos foros alternativos, para el demandante: el Estado del domicilio del demandado o del establecimiento del editor, donde el titular del derecho podrá reclamar la integridad del daño sufrido; y el Estado en el que el referido particular sea conocido, donde cabrá demandar por los daños causados únicamente en dicho Estado, estableciéndose como dijimos, anteriormente, el principio mosaico ${ }^{11}$.

23. De esta forma, evita convertir el foro especial del artículo 5,3 del Reglamento 44/2001 en un foro equivalente al general, que prima la jurisdicción del domicilio del demandado, pero igualmente elude el forum actoris, un criterio que el Reglamento ha descartado abiertamente al basarse, al igual que su antecesor, el Convenio de Bruselas, en la regla de competencia general actor sequitur forum rei ${ }^{12}$.

24. Ahora con esta Sentencia, el TJUE confirmó la aplicabilidad de la doctrina establecida en la Sentencia Shevill en el ciberespacio, a la vez que reconoció que la distribución de material en línea se debe distinguir de la distribución regional de los medios impresos, porque el primero tiene por objeto garantizar la ubicuidad ${ }^{13}$ del contenido. Asimismo, remarcó que Internet reduce la utilidad de la doctrina anterior, porque el alcance de la distribución en línea es, en principio, universal. Además, no siempre es posible cuantificar, a nivel técnico, esa distribución con certeza y precisión en relación con un Estado miembro de la UE en particular ${ }^{14}$.

25. La Sentencia adapta el criterio de conexión en el sentido de que la víctima de una lesión de un derecho de la personalidad a través de Internet puede acudir, en función del lugar en el que haya producido el daño causado en la Unión Europea por dicha lesión, a un fuero por la totalidad de ese daño ${ }^{15}$. Habida cuenta de que la repercusión de un contenido publicado en Internet sobre los derechos de la personalidad de una persona puede ser apreciada mejor por el órgano jurisdiccional del lugar en el que la supuesta víctima tiene su centro de intereses.

26. El lugar en el que una persona tiene su centro de intereses, de manera general, corresponderá a su residencia habitual. Sin embargo, una persona puede tener su centro de intereses también en un Estado miembro en el que no resida habitualmente, en la medida en que otros indicios, como el ejercicio de una actividad profesional, permitan establecer la existencia de un vínculo particularmente estrecho con ese Estado miembro. De esta forma, el criterio adoptado con el centro de interés es conforme con el

10 STJUE, de 17 de octubre de 2017, Bolagsupplysningen Ö̈, Ingrid Ilsjan contra Svensk Handel AB, asunto C-194/16 (ECLI:EU:C:2017:766), apartado 29.

${ }^{11}$ Hay que tener en cuenta que el principio mosaico concilia, por un lado, la necesidad de centralizar en un solo Estado, el del editor o el del demandado, las acciones sobre la totalidad de los daños reivindicados y, por otro, lado permite al titular del derecho de la personalidad litigar, si bien de forma limitada, allá donde se materializa un daño a un bien inmaterial, como es la propia imagen (Conclusiones del Abogado General, Marco Darmon, presentadas el 14 de julio de 1994, Fiona Shevill, Ixora Trading Inc., Chequepoint SARL y Chequepoint International Ltd contra Presse Alliance SA, apartado 46 y ss.).

12 Conclusiones del Abogado General, Michal Bobek, presentadas el 13 de julio de 2017, Bolagsupplysningen OÜ, Ingrid Ilsjan contra Svensk Handel AB, asunto C-194/16 (ECLI:EU:C:2017:554), apartado 38; Conclusiones del Abogado General, Marco Darmon, presentadas el 14 de julio de 1994, Fiona Shevill, Ixora Trading Inc., Chequepoint SARL y Chequepoint International Ltd contra Presse Alliance SA, apartado 39 y 40.

13 A.L. Calvo Caravaca/J. Carrascosa González, Derecho Internacional Privado, vol. II, $18^{a}$ ed., Comares, Granada, 2018, p. 1277.

${ }^{14}$ Hay que tenerte presente que el alcance mundial de Internet agrava la naturaleza grave de la violación de los derechos de la personalidad (Véase, A.L. Calvo Caravaca/J. Carrascosa GonzÁlez, Derecho Internacional Privado, vol. II, 18 a ed., Comares, Granada, 2018, p. 1286).

15 Miguel Asensio, P. A.: "Competencia judicial y protección de los derechos de la personalidad en Internet”, Diario La Ley, núm. 7787, Sección Tribuna, 31 enero 2012, pp. 1-6. 
objetivo de la previsibilidad ${ }^{16}$ de las normas de competencia establecido en el Reglamento 1215/2012, ya que el demandante puede determinar fácilmente el órgano jurisdiccional ante el cual puede ejercitar una acción y el demandado puede prever ante qué tribunal puede ser demandado.

\section{El centro de interés como criterio de competencia para las personas jurídicas}

27. De la lectura conjunta de las Sentencias Shevill e eDate, vistas anteriormente, se desprende que, actualmente, en caso de un supuesto ataque contra la reputación mediante la publicación de información en Internet ${ }^{17}$, cuando el demandante es una persona física puede elegir entre cuatro tipos de foro, tres de ellos plenos, ante los cuales podrían reclamarse todos los daños y perjuicios causados, y el cuarto parcial, en el que la acción habría de limitarse a los daños soportados en el territorio de ese Estado. Los foros plenos incluyen un foro general (del domicilio del demandado) y dos foros especiales (el lugar en el que se originó el daño, que suele coincidir con el foro general en la mayor parte de los casos, y el lugar en el que el demandante tiene su centro de intereses). Además, es posible que el resto de Estados miembros se consideren foros parciales, dado que en todos ellos se puede acceder a la información publicada en Internet $^{18}$.

28. Ahora, debemos tener presente que en la Sentencia que comentamos, la recurrente es una persona jurídica, que solicita que se rectifique la información y se supriman los comentarios de su sitio web y, subsidiariamente, una indemnización por daños y perjuicios. De esta forma, se viene a plantear si el forum actoris, basado en el centro de intereses, debería extenderse a las personas jurídicas, ampliando el alcance determinado en la Sentencia eDate.

29. Esta cuestión se desarrolla en respuesta a la segunda y tercera cuestión prejudicial, haciendo extensible el criterio de conexión del centro de interés a las personas jurídicas, estableciendo que aquel se sitúa en el lugar en el que su reputación comercial es mayor, y, por lo tanto, debe determinarse en función del lugar en el que ejerce la parte esencial de su actividad económica. La ubicación del domicilio no constituye en sí misma un criterio decisivo en el marco de tal análisis, ya que todo va a depender del lugar donde lleve su actividad, ya que puede darse que la totalidad o una parte esencial de éstas las lleve a cabo en otro Estado miembro en el que está situado dicho domicilio y, en consecuencia, la reputación de que goza allí es más importante que en cualquier otro Estado miembro. De esta forma, en lo que respecta al centro de intereses de las personas jurídicas, normalmente el daño puede afectar a su actividad profesional. En el caso de las personas jurídicas con ánimo de lucro, esto es, sociedades, es probable que la competencia se atribuya al Estado miembro donde se registra la mayor parte de su volumen de negocios ${ }^{19}$.

30. En consecuencia, el TJUE interpreta que el artículo 7,2 del Reglamento 1215/2012 (antiguo artículo 5,3 del Convenio de Bruselas y artículo 5,3 del Reglamento 44/2001) debe interpretarse en el sentido de que una persona jurídica, que afirma que la publicación de información inexacta sobre ella en Internet y la no supresión de comentarios que la afectan han vulnerado sus derechos de la personalidad, puede presentar una demanda al objeto de obtener la rectificación de dicha información, la supresión de esos comentarios y la reparación de la totalidad del perjuicio sufrido ante los tribunales del Estado miembro en el que se halla su centro de intereses.

16 Considerando 15 del Reglamento 1215/2012, de 12 de diciembre de 2012, relativo a la competencia judicial, el reconocimiento y la ejecución de resoluciones judiciales en materia civil y mercantil (refundición).

17 M.Eslava Rodríguez, "el locus delicti commissi en los ilícitos contra la vida privada cometidos a través de Internet", Informática y Derecho, 34, 20014, pp. 15-38.

${ }_{18}$ Conclusiones del Abogado General, Michal Bobek, presentadas el 13 de julio de 2017, Bolagsupplysningen OÜ, Ingrid Ilsjan contra Svensk Handel AB, asunto C-194/16 (ECLI:EU:C:2017:554), apartado 9.

19 Asimismo, el Abogado General plantea que se desarrolle un criterio también para las personas jurídicas sin ánimo de lucro, es probable que se atribuya al lugar donde se sitúe la mayor parte de sus "clientes" (en el sentido más amplio del término). En ambos supuestos, lo más plausible es que sea en ese Estado miembro donde más se va a acusar el ataque a su reputación y, por tanto, a su existencia como profesional. (Conclusiones del Abogado General, Michal Bobek, presentadas el 13 de julio de 2017, Bolagsupplysningen OÜ, Ingrid Ilsjan contra Svensk Handel AB, asunto C-194/16 (ECLI:EU:C:2017:554), apartado 104). 


\section{E. Competencia judicial para la supresión y rectificación de información inexacta}

31. Esta cuestión fue el objeto de la primera cuestión prejudicial planteada por el Tribunal Supremo de Estonia, pidiendo así orientación en relación a cómo interpretar el artículo 7,2 del Reglamento 1215/2012 en relación a las acciones dirigidas a la rectificación de la información inexacta y a la supresión de los comentarios lesivos de sus derechos ante los tribunales de cada Estado miembro en cuyo territorio la información publicada en Internet sea o haya sido accesible, por el perjuicio ocasionado en el correspondiente Estado miembro; es decir, como dice el Abogado General en sus Conclusiones, "si la competencia de los órganos jurisdiccionales estonios se limita al perjuicio causado a la recurrente en territorio estonio, ¿pueden pronunciarse sobre la solicitud de que se ordene al demandado rectificar y suprimir en Suecia la información lesiva en su totalidad?".

32. El TJUE atendiendo a la ubicuidad de los datos y contenidos en internet, es decir, que el alcance de la difusión de contenidos publicados en ella es, en principio, universal ${ }^{20}$, considera que la rectificación de información y supresión de los comentarios es una solicitud única e indivisible, por lo que solo puede presentarse ante un tribunal con competente respecto de la totalidad del daño causado, y no ante un tribunal que carece de esta competencia, en virtud de la jurisprudencia analizada anteriormente en la Sentencia Shevill, con lo que está optando por mantener la teoría del mosaico.

33. De esta forma, entiende que el que el artículo 7,2 del Reglamento 1215/2012 debe interpretarse en el sentido de que una persona que alega que la publicación de información inexacta sobre ella en Internet y la no supresión de comentarios que la afectan han vulnerado sus derechos de la personalidad no puede presentar una demanda al objeto de obtener la rectificación de esa información y la supresión de esos comentarios ante los tribunales de cada Estado miembro en cuyo territorio la información publicada en Internet sea o haya sido accesible.

34. No obstante, se aparta de la postura mantenida por el Abogado General, que considera, acertadamente, que no es apropiado mantener la citada teoría, ya que si, hipotéticamente, se estableciera que la acción de la recurrente está fundada y que los órganos jurisdiccionales estonios gozan de competencia judicial internacional respecto del perjuicio causado a la recurrente en Estonia, ese órgano jurisdiccional también sería competente para ordenar la medida de reparación solicitada, siempre y cuando esa medida esté prevista en el Derecho interno ${ }^{21}$. El mantenimiento de la tesis mosaico implicaría un problema en relación a que, si los 28 foros a los que puede atribuirse la competencia judicial también son competentes para emitir órdenes judiciales, es posible que se dicten y notifiquen varias órdenes redactadas de forma distinta contra el demandado en relación con la misma conducta que debe llevar a cabo o abstenerse de llevar a cabo ${ }^{22}$.

\section{Conclusiones}

35. Con la Sentencia Bolagsupplysningen OÜ, Ingrid Ilsjan y Svensk Handel AB valiosa adición al conjunto de sentencias existentes sobre el artículo 7,2 del Reglamento 1215/2015, al poner de manifiesto que el forum actoris del centro de interés puede ser extensible a las personas jurídicas que

20 STJUE, de 25 de octubre de 2011, eDate Advertising GmbH y X y Olivier Martinez, Robert Martinez y MGN Limited (ECLI:EU:C:2011:685), apartados 48, 42 y 46.

21 Como comentan A.L. Calvo Caravaca/J. Carrascosa González: "Esto se corresponderá a una buena administración de la Justicia o sustanciación adecuada. El tribunal que corresponde al "lugar del daño" es un tribunal que puede desarrollar su labor jurisdiccional de manera efectiva y real, con calidad jurídica, y a un coste reducido, esto es, de manera eficiente. Al fin y al cabo, el lugar donde se ha producido el hecho dañoso es el lugar donde, con una alta posibilidad, se deberán recabar pruebas, datos y hechos que son necesarios para que los tribunales puedan decidir adecuadamente el litigio" (A.L. CALVo CARAVACA/J. Carrascosa González, Derecho Internacional Privado, vol. II, $18^{\mathrm{a}}$ ed., Comares, Granada, 2018, pp. 1271).

${ }^{22}$ Conclusiones del Abogado General, Michal Bobek, presentadas el 13 de julio de 2017, Bolagsupplysningen OÜ, Ingrid Ilsjan contra Svensk Handel AB, asunto C-194/16 (ECLI:EU:C:2017:554), apartados 76, 78, 79 y 129. 
afirman que sus derechos de la personalidad han sido vulnerados como consecuencia de la publicación de información en Internet.

36. El centro de intereses de una persona jurídica con ánimo de lucro se encuentra en el Estado miembro donde lleva a cabo la mayor parte de sus actividades. Este Estado miembro puede ser distinto del Estado miembro en el que se encuentra su domicilio social.

37. Finalmente, en relación a la discrepancia entre el Abogado General y el TJUE, debería optarse por el criterio del Abogado General, en el sentido de que si un órgano jurisdiccional de un Estado miembro es competente para conocer de una acción por daños y perjuicios en materia extracontractual o delictual, debe poder pronunciarse sobre todas las medidas de reparación previstas por el Derecho interno, salvo que se declare que la competencia mosaico de Shevill permite única y exclusivamente a un órgano jurisdiccional nacional conocer de la acción por daños y perjuicios; esto es, indemnización económica, sin pronunciarse sobre ninguna otra pretensión. Ahora bien, sería difícil determinar la base jurídica de una limitación tan radical de la competencia de los órganos jurisdiccionales nacionales, así como la manera en que los órganos jurisdiccionales nacionales podrían sustanciar un procedimiento en el que sus competencias se restringieran de esa forma. 